\title{
Role of Al(III) in Zn-Based Electrode Synthesis for Supercapacitor
}

\author{
Yubin Yang, Yue Yu, Shaomin Zhu*, Hongfeng Xu \\ Liaoning Provincial Key Laboratory of New Energy Battery, Dalian Jiaotong University, Dalian, China \\ Email: ^smzhu91@126.com
}

How to cite this paper: Yang, Y.B., Yu, Y., Zhu, S.M. and Xu, H.F. (2020) Role of $\mathrm{Al}(\mathrm{III})$ in $\mathrm{Zn}$-Based Electrode Synthesis for Supercapacitor. Materials Sciences and Applications, 11, 659-667.

https://doi.org/10.4236/msa.2020.1110044

Received: August 2, 2020

Accepted: October 16, 2020

Published: October 19, 2020

Copyright (อ 2020 by author(s) and Scientific Research Publishing Inc. This work is licensed under the Creative Commons Attribution International License (CC BY 4.0).

http://creativecommons.org/licenses/by/4.0/

\begin{abstract}
Supercapacitor is considered as one of the most promising energy storage systems because of its high power density, long life and low production cost. Electrode materials play important roles in the performance of Supercapacitor (SC). In this study, Zn-based hydrotalcite structure materials are prepared by hydrothermal method. The influence of $\mathrm{Zn} / \mathrm{Al}$ ratio in precursors on electrochemical properties of electrode materials is investigated. The results show that $\mathrm{Al}(\mathrm{III})$ promotes the formation of relatively ordered active substances and participates in redox reaction on electrode surface. Specific capacitance of $\mathrm{Zn}$-based electrode reaches $2557 \mathrm{~F} \cdot \mathrm{g}^{-1}\left(1.0 \mathrm{~A} \cdot \mathrm{g}^{-1}\right)$ at $\mathrm{Zn} / \mathrm{Al}$ molar ratio of 1:1 in precursors. This method is simple and environmentally friendly. The electrode exhibits excellent electrochemical activity and stability, showing this material application prospect for supercapacitor.
\end{abstract}

\section{Keywords}

Supercapacitor, Hydrotalcite, Zn-Based Electrode, Aluminium Ion Doping

\section{Introduction}

The continuous progress of our society asks for green and sustainable development of economy, and also puts forward higher requirements for energy storage and conversion [1]. Typical energy storage devices include batteries and supercapacitors. Supercapacitor (or electrochemcial capacitors, SC) is novel energy storage system between traditional capacitor and rechargeable battery with high efficiency, practical, and environmental friendly [1] [2] [3] [4] [5]. Compared with traditional capacitors, SC has larger capacity, higher energy, wider operating temperature range and extremely long theoretical life. While compared with batteries, it has higher power density and almost no pollution. SC can be divided into double layer capacitors and pseudocapacitors. Charge storage in SC is 
mainly based on surface processes or surface reactions of electrode materials [2] [3]. Researches on SC mainly focus on how to increase energy density while maintain high power density in recent years. Carbon materials, conductive polymer materials and metal oxide/hydroxide materials are all applied for electrode materials to achieve above goals [4] [5].

Layered double metal hydroxides material (Layered double hydroxides, LDHs), including hydrotalcite and hydrotalcite-like compounds, is a kind of ideal SC electrode materials [5]. Large theoretical specific surface area of this material can provide certain double-layer capacitance. Mean while, active metal ions on surface of layers can act as active sites for electrochemical reactions, providing pseudocapacitance. Only a few atoms thickness of LDHs nanosheet makes this material not only have relatively high specific surface area, but also can fully expose electrochemical active sites. In LDHs structure, bivalent and trivalent metal ions (M(II) and $\mathrm{M}(\mathrm{III})$ ions) coordinate with $\mathrm{OH}$ groups located at the apex of octahedral and form nanosheet plane. Replacement of M(III) ions makes entire laminate positively charged, which must be balanced by anions with equal charge located interlayers. Since the proportion of M(II) and M(III) ions and the composition of LDHs are controllable, reasonable assembly of ions can be carried out according to the actual needs of electrochemical activity and specific conditions [5] [6].

In our preliminary study, $\mathrm{Zn}$-based electrode materials were prepared which had mainly $\mathrm{Zn}_{4}(\mathrm{OH})_{6} \mathrm{CO}_{3} \cdot \mathrm{H}_{2} \mathrm{O}$ crystal structure and showed excellent electrochemical activity [7]. However, the role of $\mathrm{Al}(\mathrm{III})$ is not clear both in synthesis process and in electrochemical reaction. Whether can this layered active material still be obtained without $\mathrm{Al}(\mathrm{III})$ ? Whether does $\mathrm{Al}(\mathrm{III})$ participate in synthesis process, as well as in the electrode activity and stability? These questions are all worthy of in-depth study to optimize electrode structure and clarify synthesis process and activity mechanism. In order to answer these questions, the materials with different $\mathrm{Al}(\mathrm{III})$ amount in precursors are prepared and their electrochemical activity, stability, composition and structure are analyzed.

\section{Experimental}

\subsection{Preparation of Electrode}

Zn-based electrode materials are prepared by hydrothermal method as literature

[6] [7]. Typical synthesis steps are as follows. Zinc nitrate and aluminum nitrate are used as precursors and urea as precipitant. Moles of urea added are 5 times of that of metal ions. The above substances are dissolved in $36 \mathrm{ml}$ deionized water and then transferred to a $50 \mathrm{ml}$ hydrothermal kettle. Pretreated nickel foam $(1 \times 1 \mathrm{~cm})$ is added in. After $12 \mathrm{~h}$ hydrothermal reaction at $120^{\circ} \mathrm{C}$, the product is washed to neutral, and dried at $60^{\circ} \mathrm{C}$ overnight. The sample is labeled as LHDs-a:b, with a:b of $\mathrm{Zn}(\mathrm{II})$ and $\mathrm{Al}(\mathrm{III})$ molar ratio in precursor.

Active carbon (AC) electrode on $1 \times 1 \mathrm{~cm}^{2}$ nickel foam is prepared to assemble LDHs//AC supercapactior, in which mass proportion of AC (BP2000), ace- 
tylene black and Poly tetra fluoroethylene (PTFE) is 8:1:1.

\subsection{Characterization}

Field emission scanning electronic microscope (FESEM, JEOLJEM-6360LV, Japan) is used to analysize morphology of sample. The accelerating voltage is 20 $30 \mathrm{kV}$. The sample was processed with gold spraying before testing. X-ray diffraction (XRD) test is performed on X'pert proSuper ray diffractometer of PAN Analytical (Holland). Copper target is used as light source $(\lambda=1.5432 \mathrm{~nm})$ with graphite monochromator. The tube voltage is $40 \mathrm{kV}$, while tube current is $100 \mathrm{~mA}$.

Three electrodes system is used to analyze electrode in $6 \mathrm{~mol} \cdot \mathrm{L}^{-1} \mathrm{KOH}$ electrolyte with as-prepared LDHs sample, $\mathrm{Pt}$ mess, and $\mathrm{HgO} / \mathrm{Hg}$ electrode are used as working electrode, counter electrode, and reference electrode, respectively. Electrochemical performance of LDHs electrode and LDHs//AC was evaluated on CHI660E and LANHE electrochemical workstation (China).

\section{Results and Discussion}

\subsection{Role of Al(III) in Electrochemical Activities of Electrode}

Influences of $\mathrm{Zn} / \mathrm{Al}$ ratio on electrochemical properties of $\mathrm{LDHs}$ electrode are investigated, as shown in Figure 1(a). It can be seen that cyclic voltammetry curves (CV) $\left(0.01 \mathrm{~V} \cdot \mathrm{s}^{-1}\right)$ show obvious Redox peaks, indicating that all electrodes present typical Faraday pseudocapacitance characteristic [8]. Current response reaches maximum value for the sample with ratio of $\mathrm{Zn} / \mathrm{Al} 1: 1$ in precursors, while the minimum of peak potential difference occurs on LDHs-5:1. As the ratio of $\mathrm{Zn} / \mathrm{Al}$ decreased, the peak potential difference increased. The above results indicate that increase of $\mathrm{Al}(\mathrm{III})$ in precursor is conducive to obtaining higher current response value to some extent however peak potential difference increases. Therefore, in order to optimize both electrochemical activity and reversibility of electrode, it is necessary to analyze appropriate $\mathrm{Al}(\mathrm{III})$ amount in precursor.

Figure 1(b) shows galvanostatic charge and discharge curves of as-prepared LDHs materials at current density of $1 \mathrm{~A} \cdot \mathrm{g}^{-1}$. It can be seen that all curves present obvious charge-discharge platforms, corresponding to Redox peaks in CV test, indicating Faraday pseudocapacitance characteristics of electrode within investigated potential range [9].

Discharging time of electrode $\left(1.0 \mathrm{~A} \cdot \mathrm{g}^{-1}\right)$ increases with $\mathrm{Al}(\mathrm{III})$ ratio in precursors. Specific capacitance curves under different current densities are shown in Figure 2(a). It can be seen that the maximum specific capacitance achieve about $2557 \mathrm{~F} \cdot \mathrm{g}^{-1}$ on LDHs-1:1 electrode, which is much higher than that of other $\mathrm{Zn} / \mathrm{Al}$ proportional electrode materials, and also higher than that of other hydrotalcite type materials reported [10] [11]. Energy density and power density of LDHs electrode are shown in Figure 2(b). LDHs electrode material has higher energy and power performance when $\mathrm{Zn} / \mathrm{Al}$ ratio is 1:1 in precursors. Energy density of LDHs-1:1 reaches $89.5 \mathrm{Wh} \cdot \mathrm{kg}^{-1}$ when power density is $2000 \mathrm{~W} \cdot \mathrm{kg}^{-1}$. 
EIS results of LDHs electrode are shown in Figure 3. EIS spectrum present linear tendency with an approximately $90^{\circ}$ angle to $\mathrm{X}$-axis at low frequency region,
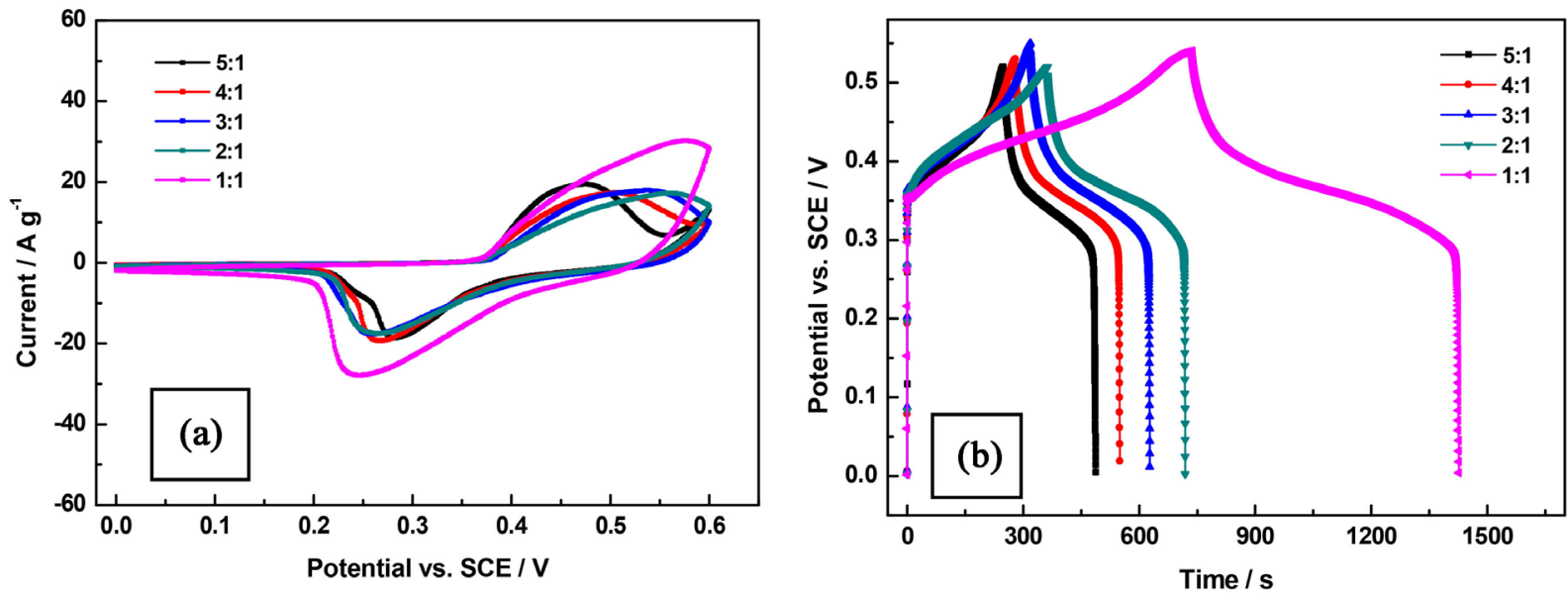

Figure 1. (a) CV curves at $0.01 \mathrm{~V} \cdot \mathrm{s}^{-1}$ and (b) galvanostatic charge/discharge curves at $1 \mathrm{~A} \cdot \mathrm{g}^{-1} \mathrm{of} \mathrm{LDHs}$ electrodes with different $\mathrm{Zn} / \mathrm{Al}$ ratio in precursors.
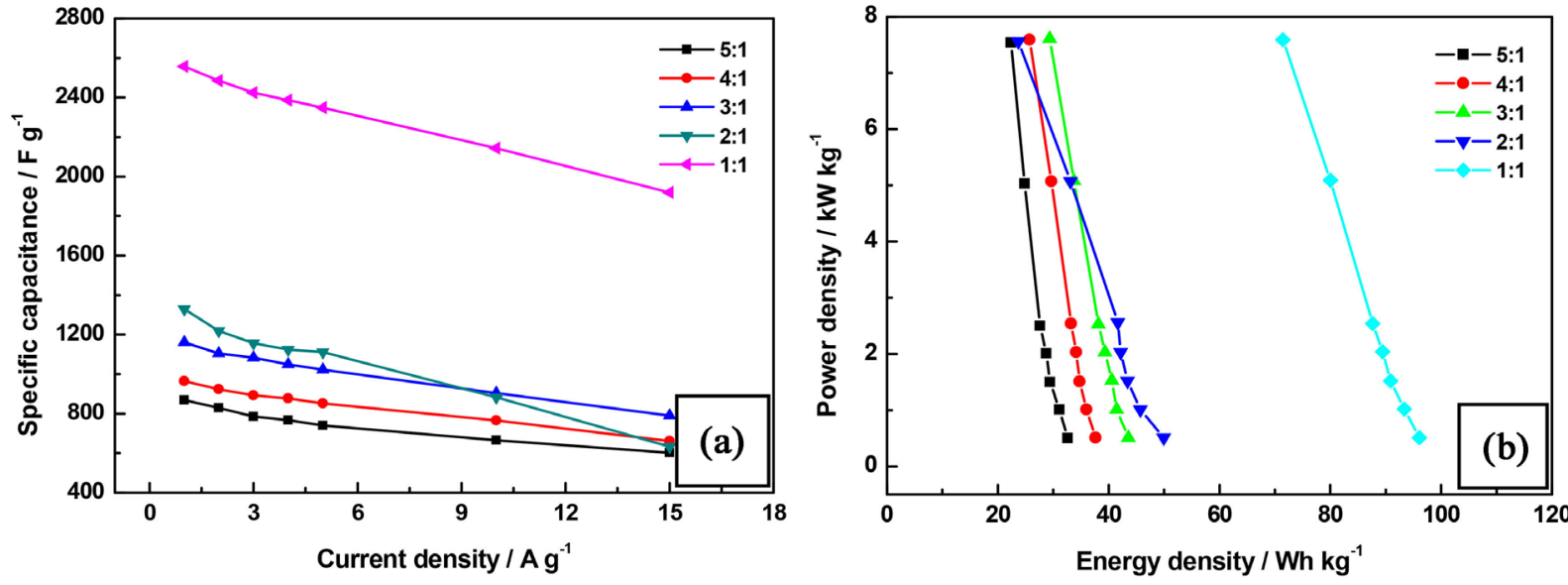

Figure 2. (a) Specific capacitance of electrodes derived from galvanostatic charge/discharge curves and (b) Ragone plots of $\mathrm{LDHs}$ electrodes with different $\mathrm{Zn} / \mathrm{Al}$ ratio in precursors.
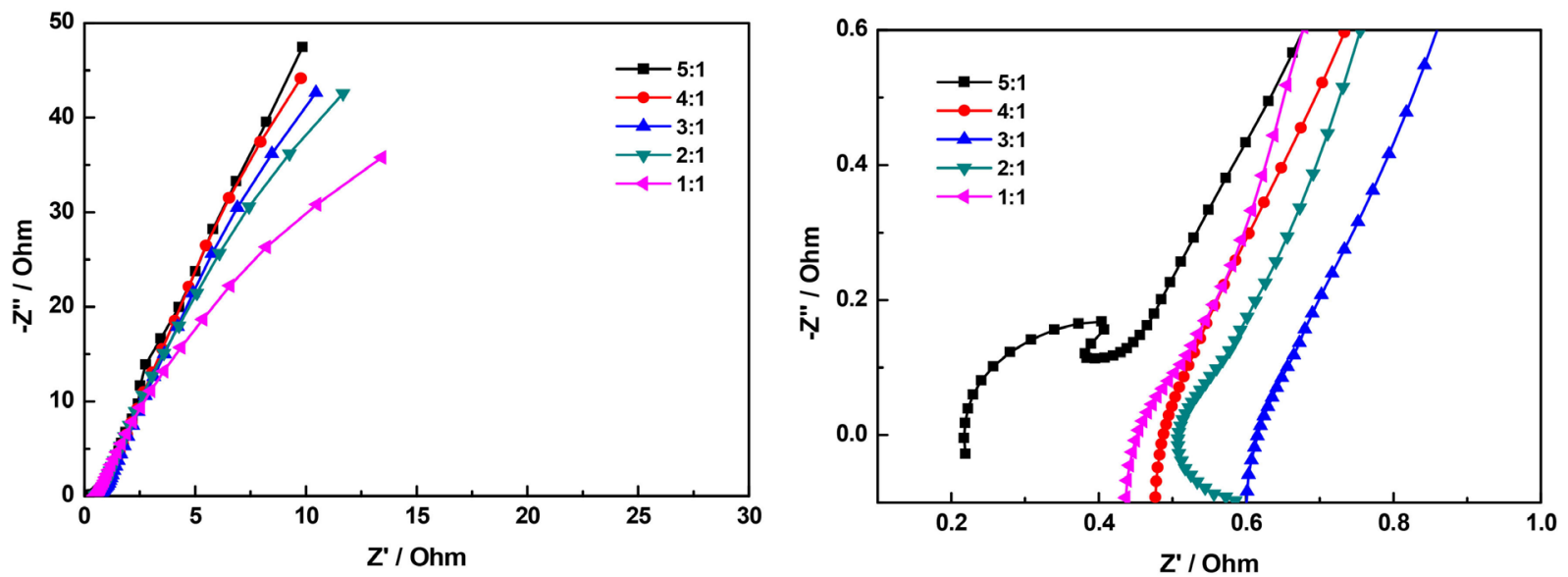

Figure 3. Nyquist plots of LDHs electrodes with different $\mathrm{Zn} / \mathrm{Al}$ ratio in precursors (Right: Local enlarged image). 
indicating good capacity performance of electrodes [12]. Further analysis shows that the slope of the line in low frequency region decreases with increase of $\mathrm{Al}(\mathrm{III})$ amount in precursor. At the same time, equivalent series resistance increases at first and then decreases with $\mathrm{Zn} / \mathrm{Al}$ ratio in precursors [6].

\subsection{Role of Al(III) in Composition and Structure of Materials}

XRD patterns of products are shown in Figure 4. It can be seen that diffraction peaks strength increase slightly with $\mathrm{Al}(\mathrm{III})$ amount in precursors, however there is no significant change of peak position in XRD patterns. Most of these diffraction peaks correspond to characteristic diffraction peaks of $\mathrm{Zn}_{4}(\mathrm{OH})_{6} \mathrm{CO}_{3} \cdot \mathrm{H}_{2} \mathrm{O}$ (JCPDS No.011-0287). Some possible crystalline phases, such as $\mathrm{AlO}(\mathrm{OH})$ (JCPDS No.021-1307) and $\mathrm{Zn}(\mathrm{OH})_{2}$ (JCPDS No.089-0138), are not observed in $\mathrm{XRD}$ spectrum. This result shows that $\mathrm{Al}(\mathrm{III})$ in precursor promotes the formation of $\mathrm{Zn}_{4}(\mathrm{OH})_{6} \mathrm{CO}_{3} \cdot \mathrm{H}_{2} \mathrm{O}$ crystal phase.

Further comparison with $\mathrm{Zn}_{4}(\mathrm{OH})_{6} \mathrm{CO}_{3} \cdot \mathrm{H}_{2} \mathrm{O}$ standard spectrum shows that peak positions of as-products move to higher $2 \theta$ values slightly, accompanied by $\mathrm{d}$ values decrease simultaneously (Table 1 ). For example, the diffraction peak at $2 \theta=12.829^{\circ}$ in $\mathrm{Zn}_{4}(\mathrm{OH})_{6} \mathrm{CO}_{3} \cdot \mathrm{H}_{2} \mathrm{O}$ standard spectrum has moved to $2 \theta=$ $12.965^{\circ}$ when $\mathrm{Zn} / \mathrm{Al}$ ratio $5: 1$ in precursors. It can be speculated from these

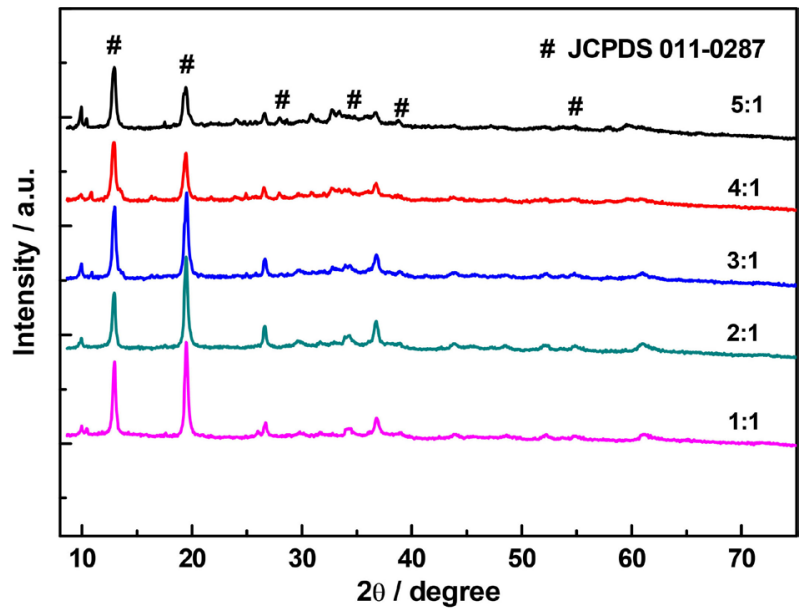

Figure 4. XRD patterns of $\mathrm{LDHs}$ with different $\mathrm{Zn} / \mathrm{Al}$ ratio in precursors.

Table 1. Calculations of $d$ value of LDHs samples from XRD characteristics.

\begin{tabular}{cccccc}
\hline Sample & $\mathbf{2 \theta}\left({ }^{\circ}\right)$ & $\mathrm{d}(\mathrm{nm})$ & Sample & $\mathbf{2 \theta}\left(^{\circ}\right)$ & $\mathrm{d}(\mathrm{nm})$ \\
\hline LDHs-5:1 & 12.965 & 0.6829 & LDHs-1h & 12.922 & 0.6851 \\
LDHs-4:1 & 12.907 & 0.6859 & LDHs-2h & 12.926 & 0.6849 \\
LDHs-3:1 & 12.891 & 0.6868 & LDHs-3h & 12.892 & 0.6867 \\
LDHs-2:1 & 12.934 & 0.6845 & LDHs-8h & 12.788 & 0.6923 \\
LDHs-1:1 & 12.931 & 0.6846 & LDHs-12h & 12.891 & 0.6868 \\
& & & LDHs-20h & 12.815 & 0.6908 \\
\hline
\end{tabular}

a LDHs-1h: LDHs-3:1 product with $1 \mathrm{~h}$ hydrothermal process at $120^{\circ} \mathrm{C}$. 
results that a small amount of $\mathrm{Al}(\mathrm{III})$ is doped into structure by substituting $\mathrm{Zn}(\mathrm{II})$, which increases positive charge amount of laminate and promotes the attraction between laminate cations and inter-laminar anions. Substitution of $\mathrm{Al}(\mathrm{III})$ results in the formation of a bimetallic composite hydroxide structure in which $\mathrm{Zn}$ (II) ions act as the main cations and a small amount of $\mathrm{Al}$ (III) doped, that is, a hydrotalcite-like structure material. Table 1 also shows that with increase of $\mathrm{Al}(\mathrm{III})$ ratio in precursors, the corresponding $\mathrm{d}$ value of the main diffraction peak does not change significantly, which indicates that $\mathrm{Al}(\mathrm{III})$ doping in $\mathrm{Zn}_{4}(\mathrm{OH})_{6} \mathrm{CO}_{3} \cdot \mathrm{H}_{2} \mathrm{O}$ structure is very limited.

Since $\mathrm{Al}(\mathrm{III})$ doping in $\mathrm{Zn}_{4}(\mathrm{OH})_{6} \mathrm{CO}_{3} \cdot \mathrm{H}_{2} \mathrm{O}$ structure is very limited, is it possible to synthesize this highly ordered product directly without $\mathrm{Al}(\mathrm{III})$ in precursors? In order to answer this question, similar synthesis process is carried with $\mathrm{Zn}(\mathrm{II})$ or $\mathrm{Al}(\mathrm{III})$ as single precursor, respectively. The morphology analyses of products are shown in Figure 5.

As we can see in Figure 5, as-products show thin layer on foam Ni surface

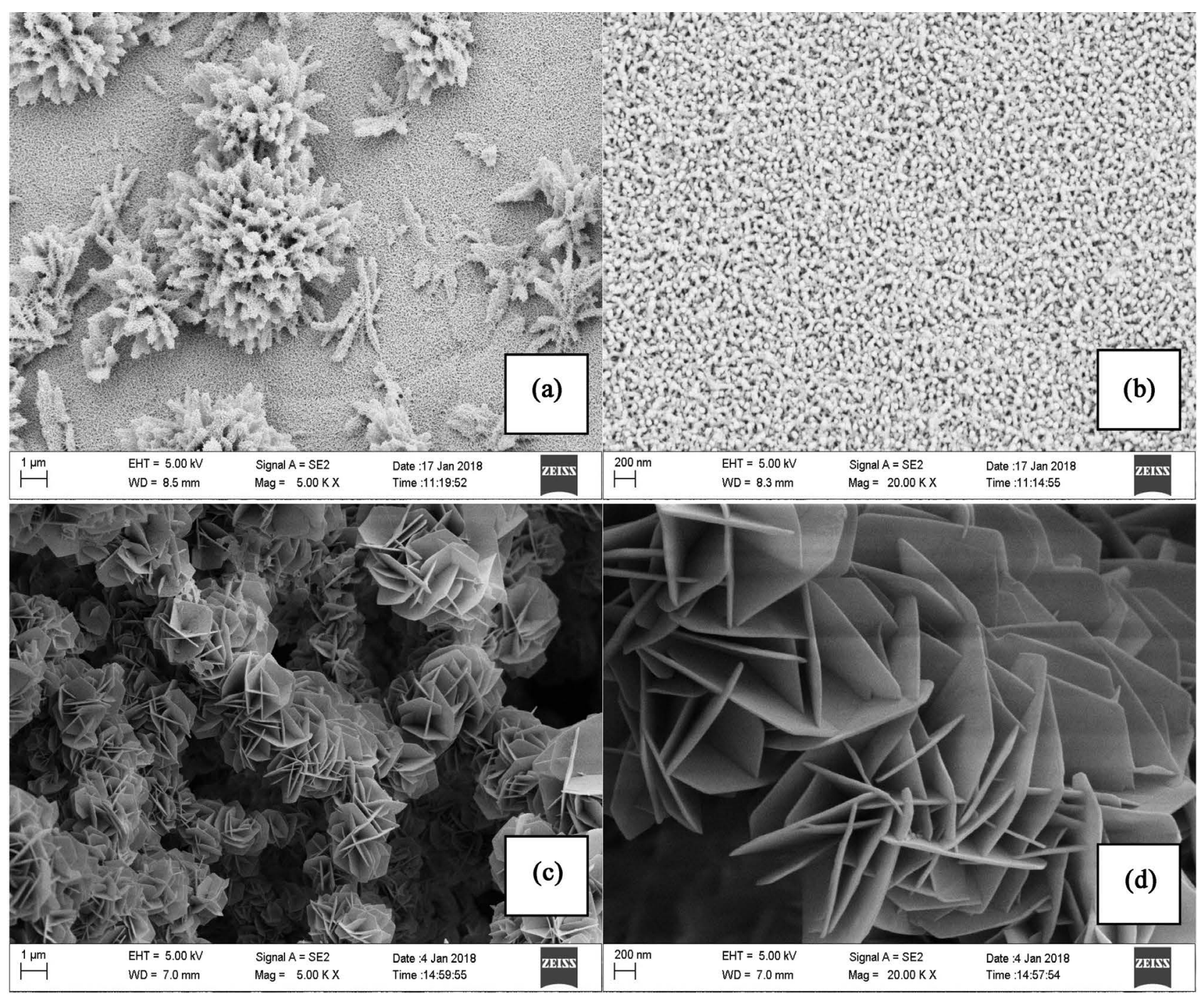

Figure 5. SEM images of as-synthesized products with different $\mathrm{Zn} / \mathrm{Al}$ ratio of ((a), (b)) 1:0 and ((c), (d)) 0:1. 
when there is only $\mathrm{Zn}$ (II) as precursor, along with some gathered dendrite flower-like clusters by aggregation and growth of nanoparticles. This morphology is completely different from that of LDHs. When only $\mathrm{Al}(\mathrm{III})$ present as precursor, the product is flower-like structure formed by self-assembly of $20-40$ $\mathrm{nm}$ thickness nanosheets. This results proves that $\mathrm{Al}(\mathrm{III})$ acts as structure-directing agent guide and plays a key role and is vital to promote the formation of active layered structure product on foam $\mathrm{Ni}$ in hydrothermal synthesis process [13].

\subsection{Contribution of Al(III) in Structure to LDHs Electrochemical Performance}

In order to investigate whether $\mathrm{Al}(\mathrm{III})$ ions in structure would contribute to electrochemical activity of electrode, $\mathrm{CV}$ tests at $0.01 \mathrm{~V} \cdot \mathrm{s}^{-1}$ are performed on samples with $\mathrm{Zn} / \mathrm{Al}$ ratio of 0:1, 1:0, and 1:1 in precursors, respectively. As shown in Figure 6(a), Redox peaks with high current response values are all observed. By comparison, it can be induced that $\mathrm{Al}(\mathrm{III})$ in structure contributes to electrode performance even if the doping is limited in composition. However, it must be noticed that the corresponding peak potential difference is larger for the sample with $\mathrm{Al}(\mathrm{III})$ as precursor only, indicating that Redox reaction on that shows lower reversibility. Therefore, limitation of $\mathrm{Al}(\mathrm{III})$ doping is practically beneficial to cycling stability of electrode and supercapacitor.

Figure 6(b) shows the cyclic stability test results of LDHs//AC asymmetric supercapacitors. As $\mathrm{Al}(\mathrm{III})$ amount increases in precursors, the cyclic stability of capacitor increases first and then decreases. After 5000 cycles of constant current test at current density of $0.5 \mathrm{~g} \cdot \mathrm{A}^{-1}$, supercapacitor assembled with LDHs-2:1 shows the best stability and remains $79.5 \%$ of initial specific capacitance. It can be concluded that it is possible to achieve higher cyclic stability by adjusting the composition and structure of $\mathrm{Zn}$-based LDHs electrode materials with proper $\mathrm{Al}(\mathrm{III})$ present.
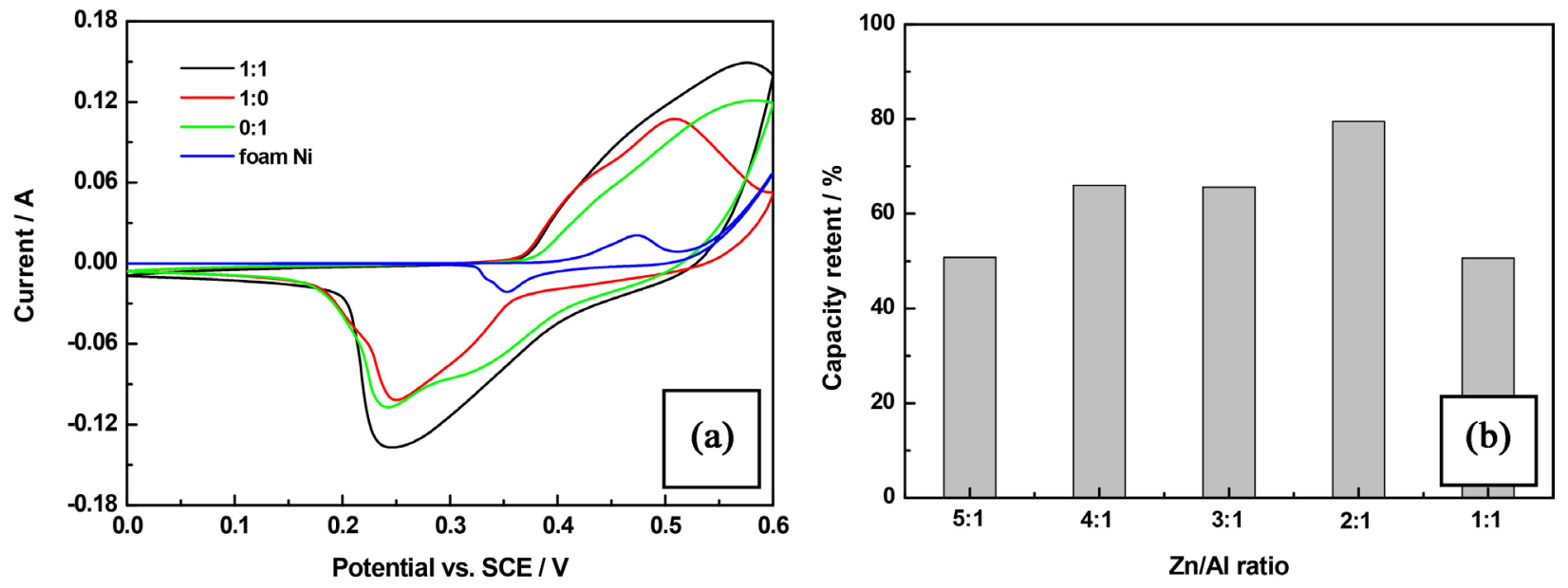

Figure 6. (a) CV curves at $0.01 \mathrm{~V} \cdot \mathrm{s}^{-1}$ of LDHs electrodes and capacity retention after 5000 cycles for LDHs//AC supercapacitors with different $\mathrm{Zn} / \mathrm{Al}$ ratio in precursors. 


\section{Conclusion}

Zn-based LDHs material with limited $\mathrm{Al}(\mathrm{III})$ substituted are synthesized by feasible hydrothermal method. The increase of $\mathrm{Al}(\mathrm{III})$ ratio in precursors is beneficial to obtain higher specific capacitance. Specific capacitance of LDHs-1:1 arrives about $2557 \mathrm{~F} \cdot \mathrm{g}^{-1}\left(1.0 \mathrm{~A} \cdot \mathrm{g}^{-1}\right)$. When power density is $2000 \mathrm{~W} \cdot \mathrm{kg}^{-1}$, energy density of the electrode reaches $89.5 \mathrm{Wh} \cdot \mathrm{kg}^{-1}$. Although $\mathrm{Al}(\mathrm{III})$ in LDHs structure is limited, it promotes relatively ordered electrode structure and participates in electrochemical reaction on electrode surface. The cyclic stability of electrode can also be improved with proper $\mathrm{Al}(\mathrm{III})$ doping. In further research, the actual doping amount of $\mathrm{Al}(\mathrm{III})$ in crystalline structure of LDHs material will be further refined, and the specific location of $\mathrm{Al}(\mathrm{III})$ in structure will be identified to optimize the electrode performance.

\section{Conflicts of Interest}

The authors declare no conflicts of interest regarding the publication of this paper.

\section{References}

[1] Wang, G., Zhang, L. and Zhang, J. (2012) A Review of Electrode Materials for Electrochemical Supercapacitors. Chemical Society Reviews, 41, 797-828.

[2] Dai, Y., Jiang, H., Hu, Y., Fu, Y. and Li, C. (2014) Controlled Synthesis of Ultrathin Hollow Mesoporous Carbon Nanospheres for Supercapacitor Applications. Industrial \& Engineering Chemistry Research, 53, 3125-3130. https://doi.org/10.1021/ie403950t

[3] Guo, X., Zhang, G., Li, Q., Xue, H. and Pang, H. (2018) Non-Noble Metal-Transition Metal Oxide Materials for Electrochemical Energy Storage. Energy Storage Materials, 15, 171-201. https://doi.org/10.1016/j.ensm.2018.04.002

[4] Han, L., Huang, H., Li, J., Yang, Z. and Pan, L. (2019) Novel Zinc-Iodine Hybrid Supercapacitors with Boosted Energy Density Using Redox Iodide Ion Electrolyte and B, N Dual Doped Carbon Electrode. Journal of Materials Chemistry A, 7, 24400-24407.

[5] Li, P., Jiao, Y., Yao, S., Wang L. and Chen, G. (2019) Dual Role of Nickel Foam in NiCoAl-LDH Ensuring High-Performance for Asymmetric Supercapacitors. New Journal of Chemistry, 43, 3139-3145.

[6] Gou, J., Xie, S. and Liu, C. (2018) Flower-Like Ni-Co Hydroxides on Ni Foam for High-Performance Supercapacitor Applications. New Journal of Chemistry, 42, 4175-4181.

[7] Yang, Y.B., Fan, X.M., Zhu, S.M. and Xu, H.F. (2020) Study on Capacitance of $\mathrm{Zn}$-Based Electrode in Redox Electrolyte System. Journal of Materials Science and Chemical Engineering, 8, 35-43. https://doi.org/10.4236/msce.2020.81004

[8] Zhang, Y., Ma, M., Yang, J., Su, H., Huang, W. and Dong, X. (2014) Selective Synthesis of Hierarchical Mesoporous Spinel $\mathrm{NiCo}_{2} \mathrm{O}_{4}$ for High-Performance Supercapacitors. Nanoscale, 6, 4303-4308.

[9] Zheng, Y., Shen, K., Wu, Z., Wang, X. and Kong, X. (2012) Electrodeposition of Zn-Doped $\alpha$-Nickel Hydroxide with Flower-Like Nanostructure for Supercapacitors. Applied Surface Science, 258, 8117-8123. 
https://doi.org/10.1016/j.apsusc.2012.05.005

[10] Li, M., Liu, F., Cheng, J.P., Ying, J. and Zhang, X.B. (2015) Enhanced Performance of Nickel-Aluminum Layered Double Hydroxide Nanosheets/Carbon Nanotubes Composite for Supercapacitor and Asymmetric Capacitor. Journal of Alloys \& Compounds, 635, 225-232. https://doi.org/10.1016/j.jallcom.2015.02.130

[11] Jing, C., Zhang, Q., Liu, X., Chen, Y., Wang, X., Xia, L., Zeng, H., Wang, D., Zhang, W. and Dong, F. (2019) Design and Fabrication of Hydrotalcite-Like Ternary NiMgAl Layered Double Hydroxide Nanosheets as Battery-Type Electrodes for High-Performance Supercapacitors. RSC Advances, 9, 9604-9612.

[12] Waghmare, S.S., Patil, P.B., Baruva, S.K., Rajput, M.S., Deokate, R.J. and Mujawar, S.H. (2018) Hydrothermal Synthesis of $\beta-\mathrm{Ni}(\mathrm{OH})_{2}$ and Its Supercapacitor Properties. AIP Conference Proceedings, 1942, Article ID: 140059.

https://doi.org/10.1063/1.5029190

[13] Gao, X., Liu, X., Wu, D., Qian, B. and Wang, J. (2019) Significant Role of Al in Ternary Layered Double Hydroxides for Enhancing Electrochemical Performance of Flexible Asymmetric Supercapacitor. Advanced Functional Materials, 29, 1903879-1903891. https://doi.org/10.1002/adfm.201903879 